\title{
ACUTE AND SUBACUTE TOXICITY PROFILE OF (3-(2,5-DIMETHOXYPHENYL)-1-(5-METHYLFURAN-2-YL) PROP-2-EN-1-ONE, CHALCONE DERIVATIVE IN EXPERIMENTAL ANIMAL MODEL
}

\author{
NOOR AZLINA ABU BAKAR ${ }^{1,2^{*}}$, NOOR AZUIN SULIMAN ${ }^{2}$, \\ MOHD ROSLAN SULAIMAN ${ }^{1}$ and MOHD NADEEM AKHTAR ${ }^{3}$ \\ ${ }^{1}$ Department of Biomedical Sciences, Faculty of Medicine and Health Sciences, \\ Universiti Putra Malaysia, 43400 UPM Serdang, Selangor, Malaysia \\ ${ }^{2}$ Faculty of Medicine and Health Science, Universiti Sultan Zainal Abidin, Kampus Kota, \\ Jalan Sultan Mahmud, 20400 Kuala Terengganu, Malaysia \\ ${ }^{3}$ Faculty of Industrial Sciences \& Technology, University Malaysia Pahang, Pahang, \\ 26300 Gambang, Malaysia \\ *E-mail: noorazlina@unisza.edu.my
}

Accepted 10 September 2021, Published online 30 November 2021

\begin{abstract}
Evaluation of toxicity induced in laboratory animals is paramount to the screening step in the assessment of the safety profile of all compounds. 3-(2,5-dimethoxyphenyl)-1-(5-methyl furan-2-yl) prop-2-en-1-one (DMPF-1); synthetic chalcone derivative has been investigated due to its pharmacological properties, including its antinociceptive and anti-inflammatory. However, the safety profile of this compound is yet to be determined. The present study seeks to highlight the toxicity effect of this compound using acute and subacute toxicity studies in the mice model. A single highest dose $(1000 \mathrm{mg} / \mathrm{kg})$ and repeated dose $(0.1,0.5,1,5$ and $10 \mathrm{mg} / \mathrm{kg})$ of DMPF-1 supplementation were executed. All toxicity study performed was supported by behavioural and body weight changes, haematological, serum biochemical analysis, macroscopic and microscopic analysis of the vital organs. The present result simplifies that DMPF-1 compound supplementation for four weeks is non-toxic as it caused no significant alteration in mice body weight and behaviour. Besides, no significant changes in haematological and biochemical parameters were observed. Further evaluation of its safety profile was confirmed by the normal architecture of the tissues organs obtained. Collectively, this report showed that DMPF-1 was safe to be consumed.
\end{abstract}

Key words: (3-(2,5-dimethoxyphenyl)-1-(5-methylfuran-2-yl) prop-2-en-1-one, acute toxicity, chalcone, DMPF-1, subacute toxicity, toxicity study

\section{INTRODUCTION}

Recently, about $80 \%$ of the world population, especially in a developed and developing country, trusted plant-based medicine as their first medical intervention (Hassan et al., 2020) and all of this was due to their pharmacological efficacy. Similar to DMPF-1 [3-(2,5-dimethoxyphenyl)-1-(5-methyl furan2-yl) prop-2-en-1-one] compound, a synthetic chalcone derivative, its anti-nociceptive and antiinflammatory activities had gained interest among researchers. The previous study showed it has potential in inhibiting various pro-inflammatory

* To whom correspondence should be addressed. mediators thus served as a potential analgesic agent (Rajajendram et al., 2015). Following the dramatic increase in the consumption of synthetic compound derived from the natural product as alternative medicine, the safety over the consumption come across as major concern worldwide. Although the consumption of herbal or traditional medicine was said to be safe, the possible adverse effect of their derivatives needs to be investigated (Das et al., 2020).

To fulfil the needs towards the safety of the compound, Organization for Economic Co-operation and Development (OECD) had entrenched animal test guidelines for testing drugs, chemicals and also food additives (OECD, 1994). By using the guideline 
provided, the toxicity over the administration of DMPF-1 was conveyed.

This study was first carried out to identify any toxicity effect produced upon administration of DMPF-1 compound including ulceration, renal and hepatotoxicity. In addition, the treatment with the single highest dose and repeated various dose ranges of this compound were applied in this study using male ICR mice subjects. Also, several parameters incorporating behavioural, physical, haematological, biochemical as well as histopathological analysis were obtained for further inspection and to provide clear evidence of any possible toxicity signature of this chalcone derivative; DMPF-1. Gross macroscopic and histopathological evaluations become the important standard in determining clinical relevance and provide value for measuring damage that occurs to the vital organs.

\section{MATERIALS AND METHODS}

\section{Drugs and reagents}

DMPF-1 was synthesized by Claisen-Schmidt condensation reaction as discussed in our previous publication (Bakar et al., 2020). Acetylsalicylic acid (ASA), (Sigma chemical, U.S.A) was used as control positive and was dissolved in saline $(0.9 \% ; \mathrm{NaCl})$. Meanwhile, a vehicle made up of ethanol, Tween 20 (Sigma chemical, U.S.A) and distilled water with a fraction of 5:5:90 (v/v) was used as control negative and as a solvent for DMPF-1 compound. The DMPF1 doses used for acute toxicity was $1000 \mathrm{mg} / \mathrm{kg}$ and for subacute toxicity ranging from $0.1-10 \mathrm{mg} / \mathrm{kg}$. The concentrations chosen was based on a preliminary experiment with volume administered was $10 \mathrm{~mL} / \mathrm{kg}$ body weight.

\section{Animals}

Adult male ICR albino mice weighing $20-25 \mathrm{~g}$, $n=6$ were used throughout this study. The male animal was chosen to avoid variability of a result obtained due to the presence of oestrous cycle in female mice and to minimise the number of animals use in this study (Boerner et al., 2018). The room temperature was kept constant at $24 \pm 1^{\circ} \mathrm{C}$ with free access to food and water ad libitum. The experiments followed the rules of ethical guidelines for the evaluation of pain on conscious animals (Abu et al., 2013) with approval by the Animal Care and Use Committee, Universiti Putra Malaysia, Serdang, Selangor.

\section{Acute toxicity study}

In acute toxicity test, a group of six mice were treated with either vehicle $(10 \mathrm{~mL} / \mathrm{kg})$, DMPF-1 (1000 $\mathrm{mg} / \mathrm{kg}$ ) and ASA (100 mg/kg) by oral gavage (p.o.) using stainless steel feeding needle with a volume of $10 \mathrm{~mL} / \mathrm{kg}$ body weight. The treatment was given only once during the first day of the experiment followed by observation for five hours with one-hour intervals only for the day of treatment. The animals were then being monitored once daily for seven consecutive days. Changes in the behaviour which represent the clinical sign of toxicity which includes salivation, diarrhoea, sedation, respiratory distress and motility were recorded (Sim et al., 2010).

\section{Subacute toxicity study}

In the subacute toxicity study, seven groups of mice $(n=6)$ were orally treated with vehicle, $0.1,0.5$, 1,5 and $10 \mathrm{mg} / \mathrm{kg}$ of DMPF-1 respectively with a volume of $10 \mathrm{~mL} / \mathrm{kg}$ body weight. The respective treatments were given daily for 28 consecutive days following standard OECD guidelines for the testing of chemicals with slight modification (Kandhare et al., 2015). Significant behavioural changes of toxicity were recorded. The body weight of the animals was measured every three days. Haematological and serum biochemical analyses were done to measure liver and kidney function. Meanwhile, necropsy, specimen collection and histological analysis were done to observe any microscopic and macroscopic changes upon DMPF-1 supplementation (Shende et al., 2015).

\section{Necropsy, specimen collection and histological analysis}

All the animals were fastened overnight with only had free access to water ad libitum before the procedure. Mice were anaesthetized with inhalation of avertine (2.5\% tribromoethanol) solution followed by the collection of blood specimen using the cardiac puncture method. The animals were then euthanized by cervical dislocation. Three major organs which include the stomach, liver and kidney were harvested to further analyse the toxicity impact of DMPF-1 treatment (Shende et al., 2015). Any visible abnormality of the organs was visualized macroscopically. The stomach was cut open at the greater curvature to spot any formation of an ulcer. Afterwards, all the organs were weighed and recorded, followed by tissue processing for microscopic analysis. In the fixation procedure, $10 \%$ formalin solution $(1: 1)$ was used followed by dehydration, wax embedding, sectioning and haematoxylin and eosin staining (Jarrar et al., 2012). Scoring of ulcer lesions was carried out based on the description in Table 1.

\section{Haematological Analysis}

The blood specimen was collected in the EDTA containing tubes and were immediately analysed for the haematological analysis using Sysmex K-1000 fully automated haematological analyser. The parameters obtained for toxicity analyses including 
Table 1. Scoring of gastric ulcer lesions

\begin{tabular}{cl}
\hline Scoring & Description \\
\hline 0 & No pathology \\
1 & Mucosal oedema and petechiae \\
2 & $1-5$ small ulcers measuring $1-2 \mathrm{~mm}$ \\
3 & More than 5 small ulcers or 1 medium ulcer measuring $3-4 \mathrm{~mm}$ \\
4 & 2 or more medium ulcers or large ulcers measuring more than $4 \mathrm{~mm}$ \\
5 & Perforated ulcers \\
\hline
\end{tabular}

red blood cell (RBC), white blood cell (WBC), platelet (PLT), haemoglobin (HGB), haematocrit (HCT), means corpuscular volume (MCV), means corpuscular haemoglobin $(\mathrm{MCH})$ and means corpuscular haemoglobin concentration (MCHC) (Patel et al., 2018).

\section{Serum Biochemical Analysis}

This study was done to establish liver and kidney function. The fasting blood sample was collected into the plain tubes and they were allowed to clot. After that, they were centrifuged at 3000 r.p.m. for $10 \mathrm{~min}$ and sera were aspirated using a pipette and transferred into the microcentrifuge tube (Patel et al., 2018). The sera collected were sent to the Biochemical Department, Faculty of Veterinary Medicine, Universiti Putra Malaysia for serum biochemical analysis. Serum was examined for various parameters involving alkaline phosphatase (ALP), alanine aminotransferase (ALT), aspartate aminotransferase (AST), total bilirubin, creatinine, gammaglutamyl transpeptidase (GGT), urea and total protein using COBAS Mira S chemistry analyzer (Roche Diagnostic System).

\section{Statistical analysis}

The data collected inclusive of changes in body weight, organ weight, haematological data and serum biochemical data were analysed statistically using GraphPad Prism 5 software using One-Way Analysis of Variance (ANOVA). All values obtained were expressed as mean \pm SEM and followed by a post hoc Dunnett test to compare the treatment groups to the control group. $p$-value $<0.05$ was considered significant as compared to the vehicle-treated group.

\section{RESULTS}

\section{Acute toxicity study}

A single high dose of DMPF-1 (1000 mg/kg) treatment in an acute toxicity study was done to mimic the possible toxicity effect due to a single overdose intake of the compound. Normal increment with no significant difference in terms of body and organ weights as compared to the vehicle-treated group was recorded as illustrated in Table 2. Throughout the assay, the entire animal showed no sign of toxicity starting from the early of the treatment until seven days of observations (Table 3 ).

\section{Haematological and serum biochemical analyses in an acute toxicity study}

No significant change $(p<0.05)$ was observed in the blood film parameter comprising of $\mathrm{RBC}, \mathrm{WBC}$, PLT, HGB, HCT, MCV, MCH and MCHC. A similar result was obtained in serum biochemical analysis including ALP, ALT, AST, total bilirubin, creatinine, GGT, urea and total protein values as shown in Table 4 as compared to the vehicle-treated group.

\section{Subacute toxicity analysis}

The subacute toxicity analysis was carried out as it mimics the possible toxicity effect upon continuous daily intake of DMPF-1 compound. In terms of body weight, groups that received a dose of 0.1 until $1.0 \mathrm{mg} / \mathrm{kg}$ of DMPF-1 showed no significant difference as compared to the vehicletreated group. However, in groups that received 5.0 and $10.0 \mathrm{mg} / \mathrm{kg}$ of DMPF-1, the mean body weight of mice decreased significantly starting from day 6 until the end of the assay (Figure 1). In ASA treated group, the mean bodyweight keeps decreasing and showed significant negative changes. No symptoms of toxicity were observed as stated in Table 3.

\section{Haematological and serum biochemical analyses}

Blood film analysis of subject receiving DMPF-1 daily for 28 consecutive days indicates no significant changes $(p<0.05)$ as being compared to vehicle-treated group meanwhile groups that received ASA showed a significant increased $(p<0.05)$ in the value of RBC, WBC, PLT and HCT that indicate early toxicity sign in the animals (Table 5). As for serum biochemical analysis, no significant change $(p<0.05)$ was observed in all parameters measured in the treatment groups. However, in ASA treatment groups, there was a significant increment $(p<0.05)$ in the level of ALP, ALT, AST, GGT and total protein. 
Table 2. Initial and final body weight of mice treated with a single oral dose of $1000 \mathrm{mg} / \mathrm{kg}$ DMPF-1

\begin{tabular}{cccc}
\hline $\begin{array}{c}\text { Body } \\
\text { weight }(\mathrm{g})\end{array}$ & $\begin{array}{c}\text { Vehicle } \\
(10 \mathrm{~mL} / \mathrm{kg})\end{array}$ & $\begin{array}{c}\text { DMPF-1 } \\
(1000 \mathrm{mg} / \mathrm{kg})\end{array}$ & $\begin{array}{c}\text { ASA } \\
(100 \mathrm{mg} / \mathrm{kg})\end{array}$ \\
\hline Initial & $21.87 \pm 0.35$ & $22.25 \pm 0.36$ & $21.95 \pm 0.45$ \\
Final & $24.7 \pm 0.39$ & $24.58 \pm 0.51$ & $23.12 \pm 0.37$ \\
Changes & $2.83 \pm 0.04^{* * *}$ & $2.33 \pm 0.15^{* * *}$ & $1.17 \pm 0.08$ \\
\hline
\end{tabular}

Each row in the data represents mean \pm S.E.M for 6 animals. ${ }^{*}$ Signify the significant value of $p<0.05,{ }^{* *}$ signify the value of $p<0.01$ and ${ }^{* * *}$ signify $p<0.001$ as compared to initial body weight. ASA: acetylsalicylic acid.

Table 3. Behavioural changes of the mice treated with a repeated dose of DMPF- 1 for subsequent 28 days in subacute toxicity study

\begin{tabular}{|c|c|c|c|c|c|c|c|c|}
\hline \multirow{2}{*}{$\begin{array}{l}\text { Behaviour } \\
\text { Dose }\end{array}$} & \multirow{2}{*}{$\begin{array}{c}\begin{array}{c}\text { Vehicle } \\
(\mathrm{mL} / \mathrm{kg})\end{array} \\
10\end{array}$} & \multirow{2}{*}{$\begin{array}{c}\text { DMPF-1 }(\mathrm{mg} / \mathrm{kg}) \\
\text { Acute toxicity }\end{array}$} & \multicolumn{5}{|c|}{$\begin{array}{l}\text { DMPF-1 }(\mathrm{mg} / \mathrm{kg}) \\
\text { Subacute toxicity }\end{array}$} & \multirow{2}{*}{$\frac{\begin{array}{c}\text { ASA } \\
(\mathrm{mg} / \mathrm{kg})\end{array}}{100}$} \\
\hline & & & 0.1 & 0.5 & 1 & 5 & 10 & \\
\hline Salivation & - & - & - & - & - & - & - & - \\
\hline Diarrhoea & - & - & - & - & - & - & - & + \\
\hline Sedation & - & - & - & - & - & - & - & + \\
\hline Respiratory distress & - & - & - & - & - & - & - & + \\
\hline Motility & - & - & - & - & - & - & - & $3 / 6$ \\
\hline
\end{tabular}

Each + sign represents the presence of behavioural changes while the - sign represents the absence of behavioural changes in the animal. ASA: acetylsalicylic acids.

Table 4. Haematological and serum biochemical analyses of mice in acute toxicity study

\begin{tabular}{|c|c|c|c|c|}
\hline Blood profile & Vehicle $(10 \mathrm{~mL} / \mathrm{kg})$ & DMPF-1 (1000 mg/kg) & ASA (100 mg/kg) & Normal Value \\
\hline RBC (x106/ì ) & $8.83 \pm 0.21$ & $8.40 \pm 0.17$ & $6.98 \pm 0.49^{* *}$ & $8.0-8.9$ \\
\hline WBC (x103/iL) & $5.20 \pm 0.18$ & $5.20 \pm 0.24$ & $7.44 \pm 0.93^{*}$ & $4.5-6.0$ \\
\hline PLT (x103/í) & $1254 \pm 45.21$ & $1252 \pm 30.97$ & $1632 \pm 68.8^{* \star *}$ & $1100-1300$ \\
\hline HGB $(g / d L)$ & $13.42 \pm 0.25$ & $13.45 \pm 0.28$ & $12.82 \pm 0.43$ & $12.0-14.0$ \\
\hline HCT (\%) & $44.32 \pm 0.96$ & $45.33 \pm 1.22$ & $38.65 \pm 1.80^{*}$ & $43.0-48.0$ \\
\hline $\operatorname{MCV}(\mathrm{fL})$ & $55.52 \pm 0.84$ & $55 . .72 \pm 0.43$ & $56.10 \pm 0.97$ & $55.0-59.0$ \\
\hline $\mathrm{MCH}(\mathrm{pg})$ & $16.30 \pm 0.25$ & $16.25 \pm 0.28$ & $16.87 \pm 0.20$ & $15.0-17.0$ \\
\hline $\mathrm{MCHC}(\mathrm{g} / \mathrm{dL})$ & $29.67 \pm 0.30$ & $29.52 \pm 0.92$ & $29.48 \pm 0.26$ & $27.0-30.0$ \\
\hline \multicolumn{5}{|l|}{ Parameters } \\
\hline ALP (g/L) & $30.30 \pm 1.22$ & $29.95 \pm 0.52$ & $35.22 \pm 0.93^{* *}$ & $25.0-29.0$ \\
\hline AST (U/L) & $82.97 \pm 3.44$ & $71.65 \pm 3.87$ & $121.9 \pm 12.24^{\star *}$ & $60.0-80.0$ \\
\hline $\mathrm{ALT}(\mathrm{U} / \mathrm{L})$ & $17.10 \pm 0.87$ & $14.82 \pm 0.88$ & $30.48 \pm 3.32^{\star * *}$ & $13.0-17.0$ \\
\hline T.Bil (umol/L) & $1.30 \pm 0.15$ & $1.48 \pm 0.17$ & $0.65 \pm 0.15^{*}$ & $1.3-1.6$ \\
\hline Creat (umol/L) & $33.67 \pm 1.54$ & $33.50 \pm 0.89$ & $34.17 \pm 2.20$ & $31.0-35.0$ \\
\hline GGT (U/L) & $3.17 \pm 0.17$ & $3.33 \pm 0.21$ & $4.83 \pm 0.60^{*}$ & $3.2-3.7$ \\
\hline Urea (umol/L) & $10.38 \pm 0.58$ & $10.47 \pm 0.65$ & $13.1 \pm 0.8^{*}$ & $9.0-13.0$ \\
\hline T.Prot (g/L) & $44.4 \pm 1.73$ & $42.18 \pm 0.63$ & $60.25 \pm 3.35^{\star \star *}$ & $40.0-47.0$ \\
\hline
\end{tabular}

Each row in the data represents mean \pm S.E.M for 6 animals. * Signify the significant value of $p<0.05,{ }^{* *}$ signify the value of $p<0.01$ and ${ }^{* * *}$ signify $p<0.001$ as the compared control group. ASA: acetylsalicylic acid. 


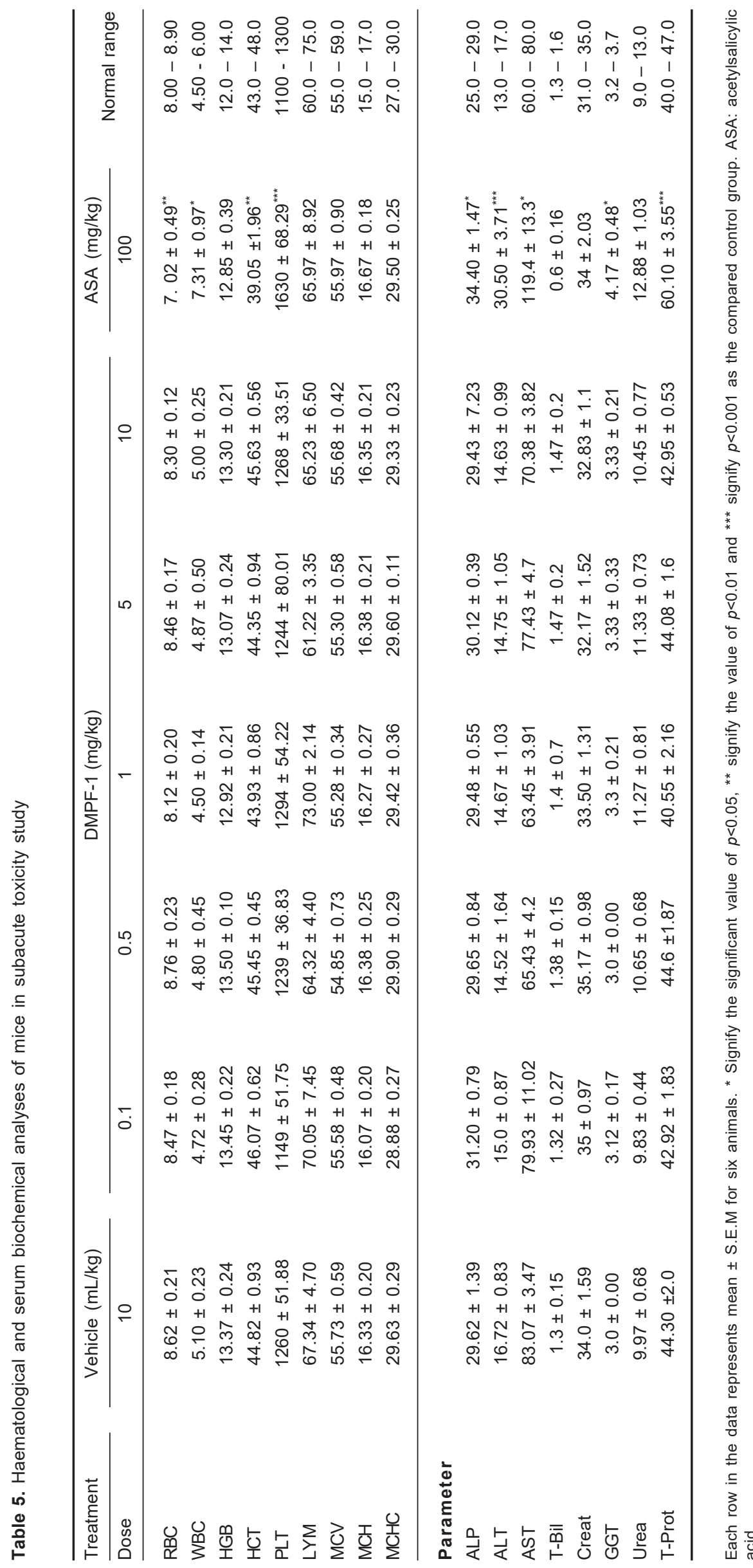




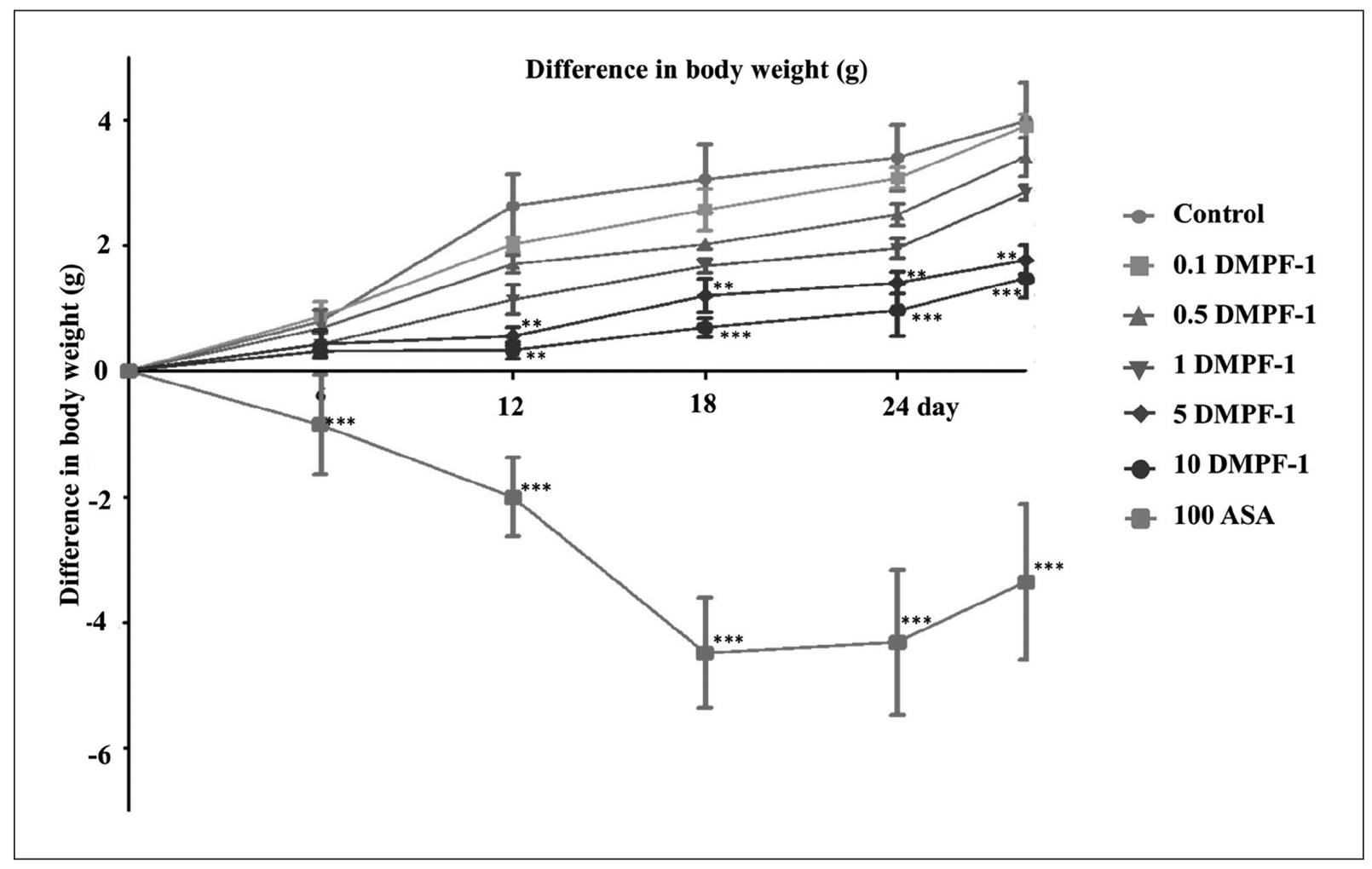

Fig. 1. The effect of DMPF-1 treatment $(0.1,0.5,1,5$ and $10 \mathrm{mg} / \mathrm{kg}$; p.o.) on mice body weight changes for 28 consecutive in subacute toxicity study. Each point in the figure represents mean \pm S.E.M for six animals. ** signify the significant value of $p<0.01$ and $* * *$ signify $p<0.001$ as the compared to vehicle-treated group. ASA: acetylsalicylic acid.

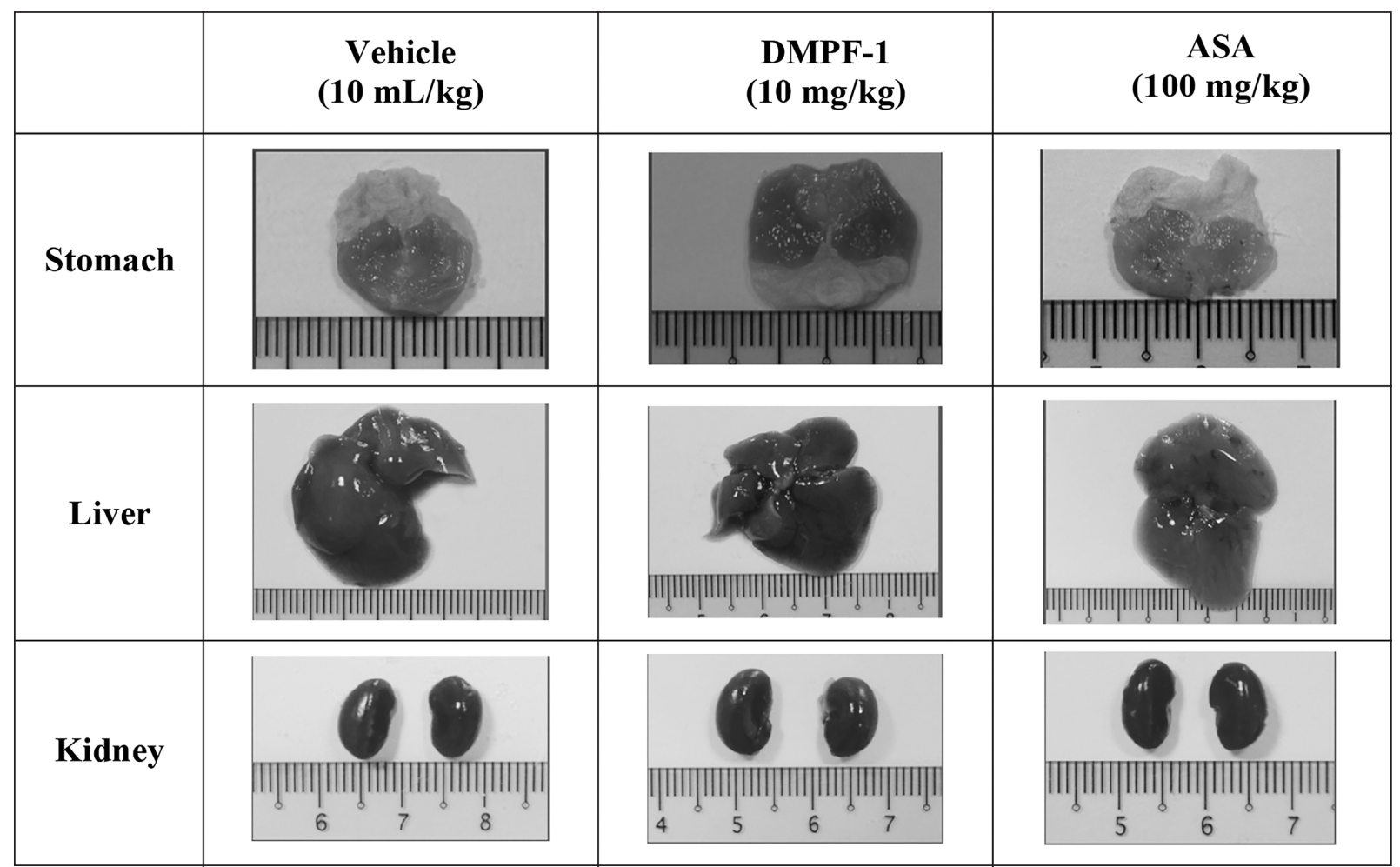

Fig. 2. Macroscopic appearance of the stomach, liver and kidney in subacute toxicity study. ASA: acetylsalicylic acid. 


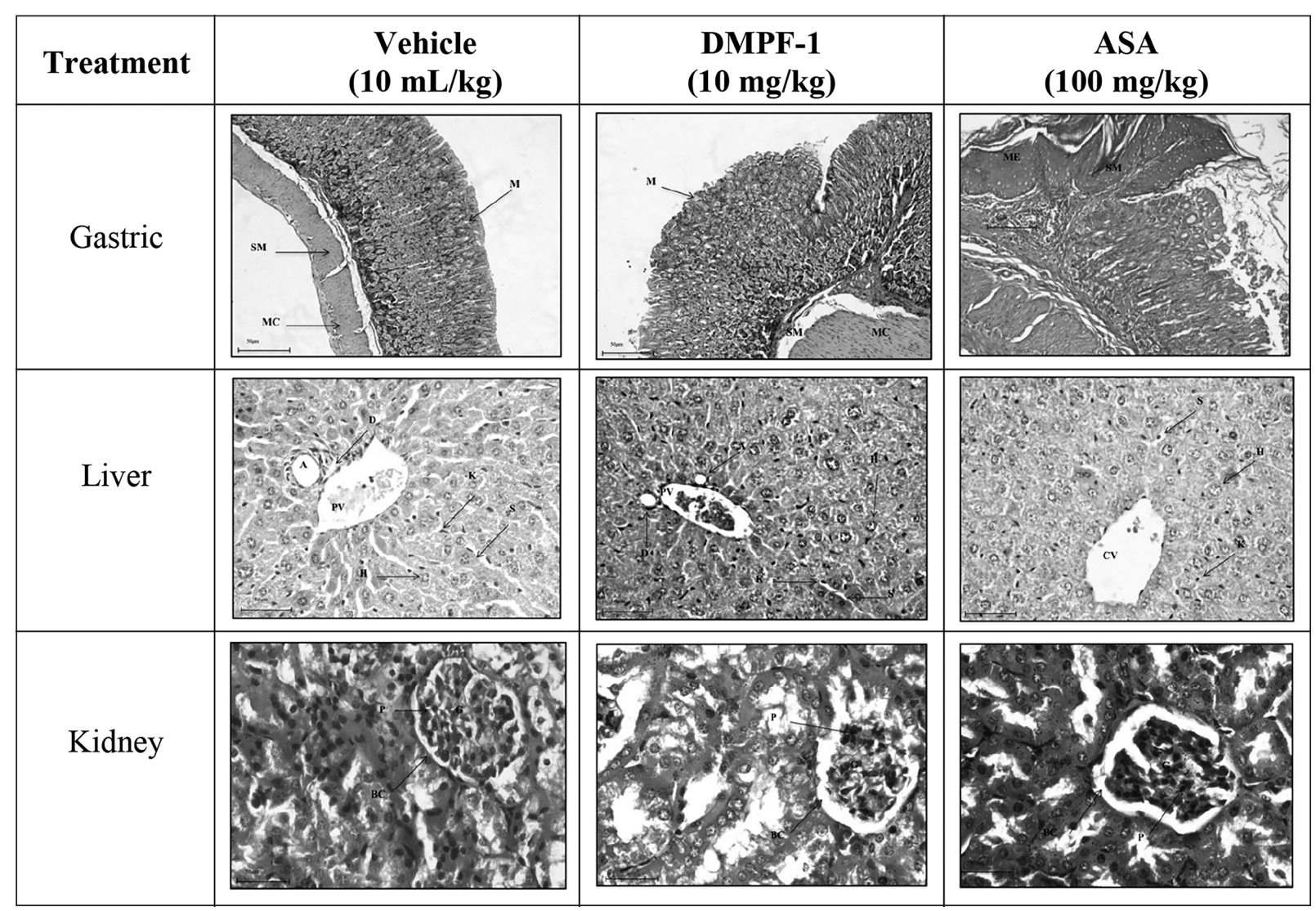

Fig. 3. Photomicrograph of stomach, liver and kidney histology of vehicle (10 mL/kg), DMPF-1 (10 mg/kg) and ASA (100 $\mathrm{mg} / \mathrm{kg}$ ) treated group with 400x magnification in subacute toxicity study. Renal corpuscle (RC), glomerulus (G), podocyte (P) and Bowman's capsule (BC).

\section{Macroscopic and microscopic analyses}

Macroscopic examination on the stomach of the animals administered with $10 \mathrm{mg} / \mathrm{kg}$ of DMPF-1 compound showed no ulcer formation as displayed in Figure 2. Based on Table 1, the macroscopic lesion scoring is 0 . As compared to the ASA treated group, there was severe disruption of the surface epithelium as can be seen which is scored 3 . Moreover, $10.0 \mathrm{mg} / \mathrm{kg}$ of DMPF-1 supplementation was unable to change any of the structure of the liver and kidney as performed in Figure 2. Evaluation on the microscopic structure of the selected said organs of the animals treated with DMPF-1 shown no apparent changes as compared to the vehicle-treated group as shown in Figure 3.

\section{DISCUSSION}

Chalcone and its derivatives received much attention within the last decades due to its convincing pharmacological properties including antiinflammatory, anti-oxidant, anti-nociceptive and antiproliferative activity (Kamaldin et al., 2013; Nordin et al., 2020). However, as chalcone has been categorized as a versatile compound by which changes in its structure offered a high degree of pharmacological efficacy and lesser toxicity, its safety profile of new chalcone analogue becomes questionable. DMPF-1, the new chalcone analogue scientifically shown to have anti-inflammatory activity by inhibiting the production of nitric oxide in murine macrophage cell line RAW 264.7 (Tham et al., 2010). Despite its beneficial pharmacological properties, current knowledge regarding its toxicity in animal model is still limited. Therefore, the present study aimed to determine any possible toxicity effect due to DMPF-1 compound supplementation using the mice model. Two phases of toxicity were evaluated which include acute single high dose and sub-acute 28 days repeated dose treatment. This study was generalized on the animal behaviour and the sign of toxicity, morbidity, motility and the effect on stomach, liver and kidney function.

In acute toxicity study, single oral treatment of DMPF-1 $(1000 \mathrm{mg} / \mathrm{kg})$ revealed interesting findings where it did not cause any significant changes in the animal behaviour. There were no signs of sedation, respiratory depression and diarrhoea were shown in the treated animals starting from the day of treatment. 
Together, no mortality was observed for the entire seven days of observation. Besides, no significant changes in body weight occur in the subjects. A similar result was obtained in a subacute toxicity study. However, the group of animals that were being treated with ASA $(100 \mathrm{mg} / \mathrm{kg})$ daily for 28 days showed pronounced changes in the animal behaviour. After three days of ASA treatment, there was a significant decrease in body weight and the animal tend to be passive as compared to the control group. Moreover, three out of six animals in the ASA treated animals died throughout the entire duration as stated in Table 3. In both studies, it is suggested that supplementation either single $1000 \mathrm{mg} / \mathrm{kg}$ or daily treatment with a dose from $0.1 \mathrm{mg} / \mathrm{kg}$ to $10 \mathrm{mg} /$ $\mathrm{kg}$ was safe for the animal without any possible side effects (Kumar, 2018).

Furthermore, to verify that DMPF-1 compound administration is practically nontoxic towards the subject, haematological and serum biochemical parameter analyses were obtained. Blood parameters were relevant as an indicator to evaluate the risk of toxicity practically in humans (Olson, 2000). In acute and subacute toxicity studies, tested haematological parameters show normal value with non-significant changes in all parameters including total RBC, WBC, PLT, HGB, HCT, MCV, MCH and MCHC. This data supported that DMPF-1 treatment is not capable to cause any systemic toxicity towards the animals.

As to support the toxicity assays, more evidence on the absence of toxicity effect upon treatment with this compound was obtained from serum biochemical parameters analysis. Serum biochemical analysis is one of the important tests in a sense to evaluate the safety of certain treatments towards liver and kidney function. Enzymatic activities of AST and ALT are among the common biochemical parameter used to measure hepatocellular tissue necrosis (Amin et al., 2010). While BUN and creatinine are the parameters used to measure kidney damage (Bao et al., 2008). An increment in the concentration of AST and ALT that exceeds the normal range in the serum indicates liver damage (Witthawaskul et al., 2003). All these incidents happen due to necrosis or damage of the membrane of the hepatocyte thus triggering the leaking of this enzyme into the bloodstream. Massive increment of these enzymes is always associated with acute hepatocellular damage induced by xenobiotics and hepatitis (Clermont and Chalmers, 1967).

In the acute toxicity study, no significant changes were found in the value of ALP), alanine ALT, AST, bilirubin TB, creatinine, GGT, Urea and also total protein. Non-significant changes in the value of ALP, ALT and AST suggest no disturbance of liver function upon DMPF-1 treatment thus verify the absence of hepatotoxicity (Bhattacharya \& Keating, 2012). Besides, it was suggested that the ability of the certain treatment to reduce the level of AST and ALT denotes the hepatoprotective of the compound (Nahar et al., 2008). Moreover, the normal value of BUN and creatinine clarify that no occurrence of renal dysfunction was observed (El Hilaly et al., 2004).

Gross comparison using macroscopic evaluation on the stomach of the animal in both assays indicates that both supplementation method does not cause any sort of ulceration. Daily supplementation until $10 \mathrm{mg} / \mathrm{kg}$ body weight for four weeks was safe as a single $1000 \mathrm{mg} / \mathrm{kg}$ bodyweight administration. There was a clear appearance of the mucosa layer without any perforation as compared to the ASA treated group (Ulser, 2016). Similarly, liver and kidney in both acute and subacute studies of DMPF-1 also expressed the absence of gross changes in both organs (Rahim et al., 2014).

Serum biochemical analysis was further supported by histopathological analysis of the liver and kidney. This analysis was additionally employed to distinctively confirm the normal appearance of the organ and normal value of serum biomarker level. Toxicity of certain compounds or treatment may influence changes to the cells including tissue necrosis. Morphological changes of necrotic cells include eosinophilic, the irregular shape of the nucleus and fragmentation of membrane (Adeneye et al., 2009). However, none of these changes was observed in the sample obtained. It was convincing that no significant abnormalities in the structure of the selective organs were obtained in DMPF-1 treatment groups.

\section{CONCLUSION}

The present result simplifies that supplementation with single highest $(1000 \mathrm{mg} / \mathrm{kg})$ and repeated dose $(0.1$ to $10 \mathrm{mg} / \mathrm{kg})$ of DMPF-1 for four weeks is non-toxic to mice as it caused no significant alteration in mice body weight. Also, administration of this compound failed to caused changes in haematological and biochemical parameters. Further evaluation was confirmed by the normal architecture of the organ tissues obtained.

\section{ACKNOWLEDGEMENTS}

The authors are thankful to the Universiti Putra Malaysia for providing the facilities for conducting the research. 


\section{REFERENCES}

Abu, N., Ho, W.Y., Yeap, S.K., Akhtar, M.N., Abdullah, M.P., Omar, A.R. \& Alitheen, N.B. 2013. The flavokawains: uprising medicinal chalcones. Cancer Cell International, 13(1): 1-7.

Adeneye, A.A., Olagunju, J.A., Banjo, A.A.F., Abdul, S.F., Sanusi, O.A., Sanni, O.O., Osarodion, B.A. \&Shonoiki, O.E. 2009. The aqueous seed extract of Carica papaya Linn. prevents carbon tetrachloride induced hepatotoxicity in rats. International Journal of Applied Research in Natural Products, 2(2): 19-32.

Amin, K.A., Hameid II, H.A. \& Abd Elsttar, A.H. 2010. Effect of food azo dyes tartrazine and carmoisine on biochemical parameters related to renal, hepatic function and oxidative stress biomarkers in young male rats. Food and Chemical Toxicology, 48(10): 2994-2999

Bakar, N.A.A., Sulaiman, M.R., Lajis, N., Akhtar, M.N. \& Mohamad, A.S. 2020. Evaluation of antinociceptive profile of chalcone derivative (3-(2, 5-dimethoxyphenyl)-1-(5-methylfuran-2-yl) prop-2-en-1-one (DMPF-1) in vivo. Journal of Pharmacy and Bioallied Sciences, 12(6): 711.

Bao, L., Yao, X.S., Tsi, D., Yau, C.C., Chia, C.S., Nagai, H. \& Kurihara, H. 2008. Protective effects of bilberry (Vaccinium myrtillus L.) extract on $\mathrm{KBrO} 3$-induced kidney damage in mice. Journal of Agricultural and Food Chemistry, 56(2): 420425.

Bhattacharya, P. \& Keating, A.F., 2012. Impact of environmental exposures on ovarian function and role of xenobiotic metabolism during ovotoxicity. Toxicology and Applied Pharmacology, 261(3): 227-235.

Boerner, K.E., Chambers, C.T., Gahagan, J., Keogh, E., Fillingim, R.B. \& Mogil, J.S. 2018. Conceptual complexity of gender and its relevance to pain. Pain, 159(11): 2137-2141.

Clermont, R.J. \& Chalmers, T.C. 1967. The transaminase tests in liver disease. Medicine, 46(2): 197-207.

Das, S., Sharangi, A.B., Egbuna, C., Jeevanandam, J., Ezzat, S.M., Adetunji, C.O., Tijjani, H., Olisah, M.C., Patrick-Iwuanyanwu, K.C., Adetunji, J.B. \& Ifemeje, J.C. 2020. Health Benefits of Isoflavones Found Exclusively of Plants of the Fabaceae Family. In Functional Foods and Nutraceuticals, Springer, Cham. pp. 473-508.

El Hilaly, J., Israili, Z.H. \& Lyoussi, B. 2004. Acute and chronic toxicological studies of Ajuga iva in experimental animals. Journal of Ethnopharmacology, 91(1): 43-50.
Hassan, S., Egbuna, C., Tijjani, H., Ifemeje, J.C., Olisah, M.C., Patrick-Iwuanyanwu, K.C., Onyeike, P.C. \& Ephraim-Emmanuel, B.C. 2020. Dietary supplements: Types, health benefits, industry and regulation. In: Functional Foods and Nutraceuticals. C. Egbuna and G.D. Tupas (Eds.). Springer, Cham. pp. 23-38.

Jarrar, B.M. \& Taib, N.T. 2012. Histological and histochemical alterations in the liver induced by lead chronic toxicity. Saudi Journal of Biological Sciences, 19(2): 203-210.

Kamaldin, M.N., Akhtar, M.N., Mohamad, A.S., Lajis, N., Perimal, E.K., Akira, A., Ming-Tatt, L., Israf, D.A. \& Sulaiman, M.R. 2013. Peripheral antinociception of a chalcone, flavokawin B and possible involvement of the nitric oxide/cyclic guanosine monophosphate/potassium channels pathway. Molecules, 18(4): 4209-4220.

Kandhare, A.D., Bodhankar, S.L., Mohan, V. \& Thakurdesai, P.A. 2015. Acute and repeated doses (28 days) oral toxicity study of glycosides based standardized fenugreek seed extract in laboratory mice. Regulatory Toxicology and Pharmacology, 72(2): 323-334.

Kumar, A. 2018. Evaluation of toxicological and behavioral symptoms on deltamethrin treated albino rats. MOJ Anatomy \& Physiology, 5(1): 63.

Nahar, M., Mishra, D., Dubey, V. \& Jain, N.K. 2008. Development, characterization, and toxicity evaluation of amphotericin B-loaded gelatin nanoparticles. Nanomedicine: Nanotechnology, Biology and Medicine, 4(3): 252-261.

Nordin, N.A., Ibrahim, A.R. \& Ngaini, Z. 2020. Biological studies of novel aspirin-chalcone derivatives bearing variable substituents. Journal of Agrobiotechnology, 11(1): 20-31.

OECD. 1994. OECD Guidelines for the Testing of Chemicals. Organization for Economic.

Olson, J.A. 2000. Requirements and safety of vitamin A in humans. In: Vitamin $A$ and Retinoids: An Update of Biological Aspects and Clinical Applications. M.A. Livrea (Ed.). Birkhäuser, Basel. pp. 29-43.

Patel, A.G., Nariya, M.B. \& De, S. 2018. Acute toxicity and repeated dose 28-day oral toxicity study of metriviv syrup in female rats. Ayu, 39(2): 107.

Rahim, N.A., Hassandarvish, P., Golbabapour, S., Ismail, S., Tayyab, S. \& Abdulla, M.A. 2014. Gastroprotective effect of ethanolic extract of Curcuma xanthorrhiza leaf against ethanolinduced gastric mucosal lesions in SpragueDawley rats. BioMed Research International, 2014. 
Rajajendram, R., Tham, C.L., Akhtar, M.N., Sulaiman, M.R. \& Israf, D.A. 2015. Inhibition of epithelial CC-family chemokine synthesis by the synthetic chalcone DMPF-1 via disruption of NF- $\kappa \mathrm{B}$ nuclear translocation and suppression of experimental asthma in mice. Mediators of Inflammation, 2015.

Shende, P., Kulkarni, Y.A., Gaud, R.S., Deshmukh, K., Cavalli, R., Trotta, F. \& Caldera, F. 2015. Acute and repeated dose toxicity studies of different $\beta$-cyclodextrin based nanosponge formulations. Journal of Pharmaceutical Sciences, 104(5): 1856-1863.

Sim, K.S., Nurestri, A.S., Sinniah, S.K., Kim, K.H. \& Norhanom, A.W. 2010. Acute oral toxicity of Pereskia bleo and Pereskia grandifolia in mice. Pharmacognosy Magazine, 6(21): 67.
Tham, C.L., Liew, C.Y., Lam, K.W., Mohamad, A.S., Kim, M.K., Cheah, Y.K., Zakaria, Z.A., Sulaiman, M.R., Lajis, N.H. \& Israf, D.A. 2010. A synthetic curcuminoid derivative inhibits nitric oxide and proinflammatory cytokine synthesis. European Journal of Pharmacology, 628(1-3): 247-254.

Ulser, T. 2016. Antiulcer activity of Musa paradisiaca [banana] tepal and skin extracts in ulcer induced albino mice. Malaysian Journal of Analytical Sciences, 20(5): 1203-16.

Witthawaskul, P., Panthong, A., Kanjanapothi, D., Taesothikul, T. \& Lertprasertsuke, N. 2003. Acute and subacute toxicities of the saponin mixture isolated from Schefflera leucantha Viguier. Journal of Ethnopharmacology, 89(1): 115-121. 